\title{
Herbal approaches of leaves of the plant maytenus emarginata as anti-inflammatory and anti-nociceptive
}

\author{
Sunil Kumar*, Mathew George, Lincy Joseph \\ Department of Pharmaceutical Sciences, Sharda University, Greater Noida-201306 U.P. India
}

Received: 06-01-2022 / Revised Accepted: 30-01-2022 / Published: 01-02-2022

\begin{abstract}
The interest in Nature as a source of potential chemotherapeutic agents continues. Natural products and their derivatives represent more than $50 \%$ of all the drugs in clinical use in the world. Higher plants contribute no less than $25 \%$ of the total. During the last 40 years, at least a dozen potent drugs have been derived from flowering plants including Dioscorea species derived diosgenin from which all an ovulatory contraceptive agents have been derived; reserpine and other anti-hypertensive and tranquilizing alkaloids from Rauwolfia species; pilocarpine to treat glaucoma and dry mouth, derived from a group of South American trees (Pilocarpus species) in the Citrus family; two powerful anti-cancer agents from the Rosy Periwinkle (Catharanthus roseus); laxative agents from Cassia species and as a cardiotonic agent to treat heart failure from Digitalis species. There is a growing interest in herbal drugs, and as an example of this, the consumption of medicinal plants has doubled in the last ten years in Western Europe.
\end{abstract}

Key words: Maytenus emarginata, inflammation, anti-nociceptive and sesquiterpene

\section{INTRODUCTION}

\section{TRADITIONAL SYSTEM OF MEDICINE}

Medicinal plants and traditional knowledge nature made human and bestowed countless favors. Ironically, sickness, diseases, complications, inconsistencies and ailments grew slowly. ${ }^{[1]}$ The creator has not made any disease without any cure for it and graced the earth with numerous plants, especially for healing. It has been the necessity of man, which made him trace out the cure from the nature itself. Due to the safe status of herbal medicine, they are in great demand in the developing as well as developed countries for primary and/or daily health care. Majority of Indian population have access to or practice various traditional medicines to maintain health or treat diseases. ${ }^{[2]}$ These includes herbs that can be used either as mono-therapy or as add-on therapy. But the most important challenge faced by these formulations arises due to lack of standardization, identification and pharmacopoeial standards (Ali, M., 2009). It is thus prudent to undertake the standardization of herbal medicine used in various healthcare systems. Moreover, herbal medicines are prepared from materials of natural origin which are prone to contamination, detoriation and variation in composition. $^{[3]}$ There is a pressing need for evaluation and analysis of herbal drugs using

Address for Correspondence: Sunil Kumar, Department of Pharmaceutical Sciences, Sharda University, Greater Noida-201306 U.P. India; E-mail: sunilk8052@gmail.com

How to Cite this Article: Sunil Kumar, Mathew George, Lincy Joseph. Herbal approaches of leaves of the plant maytenus emarginata as anti-inflammatory and anti-nociceptive. World J Pharm Sci 2022; 10(02): 216-231;

https://doi.org/10.54037/WJPS.2022.100208

Copyright:2022@ The Author(s). This is an open access article distributed under the terms of the Creative Commons AttributionNonCommercial-ShareAlike 4.0 International License (CC BY-NC-SA), which allows re-users to distribute, remix, adapt, and build upon the material in any medium or format for noncommercial purposes only, and only so long as attribution is given to the creator. If you remix, adapt, or build upon the material, you must license the modified material under identical terms. 
sophisticated techniques (Chopra and Doiphode, 2002).

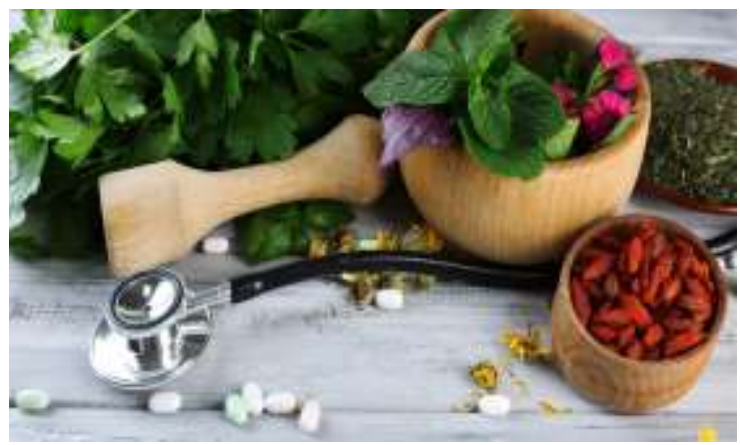

Figure:1,Source;https://static.businessworld.in/arti clelarticle_extra_large_image/1497337930_lakKq o_alternativemedicine-shutterstock.jpg

Medicinal plants constitute an effective source of traditional (Ayurvedic, Chinese, Homeopathic and Unani) and modern medicine. Germany and France, together represent $39 \%$ of the $\$ 14$ billion global retail market. Today, approximately $70 \%$ of synthetic medicines are derived from plants. India's herbal and traditional medicine industries have annual turnover of about Rs.4000-6000 crore markets and have big export potential. ${ }^{[4]}$ For export to western countries, America and Canada, their strict quality parameters and quality controls and safety and efficacy are required (Waxler, 1988).

India is one of the most important countries in the world in term of floristic diversity. About $54 \%$ of the country's land is under cultivation for food, ornamental and medicinal plant crops and approximately $19 \%$ area has varying degree of forest vegetation cover. and based developmental activities provide means of livelihood, health and opportunity for employment. India has global position in the field of traditional medicines. ${ }^{[5]}$ About $90 \%$ herbal raw drugs used in the manufacture of vegetable drugs are obtained from the wild source which is limited. There are about 45,000 plants species in India which are in abundant in the regions of eastern Himalaya, Western sea coaste and Andman and Nicobar Islands. The rich heritage of flora is due to diversified and varied agro-climatic conditions. The official documented plants with medicinal potential are 3,000 but traditional practitioner use about 8,000 vegetable drugs. India is the largest producer of medicinal herbs and approximately called the botanical garden of the world (Patwardhan et al., 2004). ${ }^{[6]}$

In Indian medicinal systems the most practitioners formulate and dispense their own recipes; hence, this requires proper documentation and research. There are currently about 2,50,000 registered medical practitioners of the Ayurvedic system; the total for all traditional systems being nearly $2,91,000$ as comparable to $7,00,000$ of the modern medicines. In rural India, $70 \%$ of the population is dependent on the traditional system of medicine. In western world also the practitioner of herbal medicines is steadily growing and approximately $40 \%$ of the population is taking herbs to treat diseases (Akerele, 1993). Plant based drugs can be used directly, i.e., they may be collected, dried and used as therapeutic agents (crude drug), or their constituents/active principles separated by various chemical processes, which are employed as medicines. ${ }^{[7]}$ The active principle or compounds with similar structure and activity are manufactured chemically to produce the synthetic drugs used in allopathic or modern system of medicine (Gadre, et al., 2001).

\section{IMPORTANCE OF PLANTS AND PLANT DERIVED PRODUCTS}

About 130 pure chemical substances extracted from some 100 species of higher plants are used in medicines throughout the world. According to a 1994 United Nations Development Project (UNDP) report, the annual value of medicinal plants derived from developing countries is about $\$ 32$ billion (Rs.3200,000 crore). ${ }^{[8]}$ Theoretically, there is the possibility of discovering 328 new modern drugs lying hidden in nearly 3,25,000 species found in tropical rain forests. There are 47 major modern plant based drugs in the world market and the predicted 328 more potential drugs have an estimated value of $\$ 147$ billion. There is massive wealth available in these collections, but what is coming in the way is the lack of standardized products, lack of reliable production technologies and the absence of pharmacological profile of drugs (Chaudhary, 1996). ${ }^{[9]}$ The importance of plants in Eastern Europe, Africa, South America, southern and central Asia countries have amalgamated the modern medicine with traditional medicine and at least $60 \%$ of the prescriptions issued in such countries contain one or more plant products (Hamburger et al., 1991). ${ }^{[10]}$ Plant secondary metabolites are not only useful as potential drugs in their natural unmodified form but are also suitable as synthetic intermediate substances for the production of useful drugs. The readily available plant steroid, diosgenin, from several species of yams (Dioscorea) and hecogenin from Sisal leaves (Agave sisalana) may be synthetically converted to steroids with anabolic, anti-inflammatory and oral contraceptive activities (Balandrin, et al., 1985). ${ }^{[11]}$ Secondary metabolites tend to be biosynthesized in specialized cell types, at only some of the life stages of the plant and are usually accumulated in much lower quantities than primary metabolites (Balandrin and Klocke 1988). ${ }^{[12]}$ Among the secondary metabolites used as therapeutic agents are alkaloids, anthraquinone 
glycosides, cardiac glycosides and lignans whose biosynthetic precursors are amino acids, polypeptides, isoprenoids and shikimate derived compounds, respectively (Tyler et al., 1988; Fransworth et al., 1985).

\section{CURRENT AND FUTURE PROSPECTS OF HERBAL DRUGS}

Approximately half $(125,000)$ of the world's flowering plant species live in the tropical forests (Ameenah, 2006). ${ }^{[13]}$ Tropical rain forests continue to support a vast reservoir of potential drug species. They continue to provide natural product chemists with invaluable compounds of starting points for the development of new drugs. ${ }^{[14]}$ The potential for finding more compounds is enormous as at date only about $1 \%$ of tropical species have been studied for their pharmaceutical potential. ${ }^{[15]}$ This proportion is even lower for species confined to the tropical rain forests. To date about 50 drugs have come from tropical plants. The existence of undiscovered pharmaceuticals for modern medicine has often been cited as one of the most important reasons for protecting tropical forests, so the high annual extinction rate is a matter for concern, to say the least (Abdin et al., 2003).It implies increasing pressure on wild plant resources and, therefore, the need for serious conservation efforts including development of cultivation techniques has never been greater. ${ }^{[16]}$ Serious over-exploitation of many medicinal plants such as Rauwolfia, Dioscorea, Swertia chirata, Valeriana, Orchis and Harpagophytum procumbens has already occurred (Wagner and Fransworth, 1990). This traditional role of international organization and universities is one that has considerable potential for expansion, so far as medicinal plants are concerned. ${ }^{[17]}$ There are some aspects of particular relevance for the rational utilization of medicinal plants and other natural products. Significant progress over the next few years will depend on the imagination and determination, which can be brought to bear on the subject (Hamberger et al., 1991).

Modern instrumentation and biological assay methods provide the possibility of developing suitable quality control criteria for herbal drugs. ${ }^{[18]}$ The structural determination of novel plant constituents can be performed with minimal delay by using a combination of sophisticated spectroscopic (UV, FT-IR, 1H NMR, 13C NMR, Mass spectroscopy) and $\mathrm{X}$ - ray crystallographic techniques. High-throughput automated bioassays are widely available, so that a detailed biological profile can be obtained easily on just a few milligrams of a natural product. ${ }^{[19]}$ Thus, there is every indication that the direct utility and promise of plants for the improvement of human health will continue well into the $21^{\text {st }}$ century (Kinghorn and Balandrin, 1993). ${ }^{[20]}$

\section{QUALITY CONTROL AND QUALITY ASSURANCE OF HERBAL DRUGS}

Plant materials and herbal remedies derived from them represent substantial portion of global market and in this respect internationally recognized guidelines for their quality control are necessary. WHO has recognized the need to ensure quality control of medicinal plant products by using modern techniques and by applying suitable standards. ${ }^{[21]}$ Several Pharmacopoeias including Indian Pharmacopoeia, British Pharmacopoeia, Pharmacopoeia of Republic of China, Japanese Pharmacopoeia and United State Pharmacopoeia do cover monograph and quality control test for few of medicinal plants used in the respective countries but basically these pharmacopoeias are designed to cater to chemical based medicine and pharmaceutical necessities by giving their standards and test methods. For pharmaceutical purpose, the quality of medicinal plant materials must be as high as that of other medicinal preparations. However, it is impossible to assay for specific chemical entity, when the bioactive ingredient is not known. Further problem is posed by those preparations, which contain heterogeneous mixtures. ${ }^{[22]}$ Directive on the analytical control of vegetable drug must take account of the fact that material to be examined has complex and inconsistent composition. ${ }^{[23]}$ Therefore, the analytical limits cannot be as precise as for the pure chemical compound (Gruenwald, J. 2008).

Vegetable drugs are inevitably inconsistent because of their composition and hence the standardization may be influenced by several factors such as age and origins, harvesting period, method of drying and so on. To eliminate some of the causes of inconsistency, one should use cultivated rather than wild plant, ${ }^{[2]}$ which are often heterogeneous in respect of the factors and consequently in their content of active principles (Gupta, A. K., 2003).

\section{CHALLENGES IN DRUG DISCOVERY FROM MEDICINAL PLANTS}

In spite of the success of drug discovery programs from plants in the past 2-3 decades, future endeavors face many challenges. Natural products scientists and pharmaceutical industries will need to continuously improve the quality and quantity of compounds that enter the drug development phase to keep pace with other drug discovery efforts. ${ }^{[25]}$ The process of drug discovery has been estimated to take an average period of 10 years and cost more than 800 million dollars (Dickson and Gagnon2004). Much of this time and money is spent on the numerous leads that are discarded during the drug discovery process. It is estimated that only one in 5000 lead compounds will successfully advance through clinical trials and be approved for use. In the drug discovery process, 
lead identification is the first step. Lead optimization (involving medicinal and combinatorial chemistry), lead development (including pharmacology, toxicology, pharmacokinetics, ADME and drug delivery), and clinical trials all take considerable time (Jachak and Saklani 2007). ${ }^{[26]}$

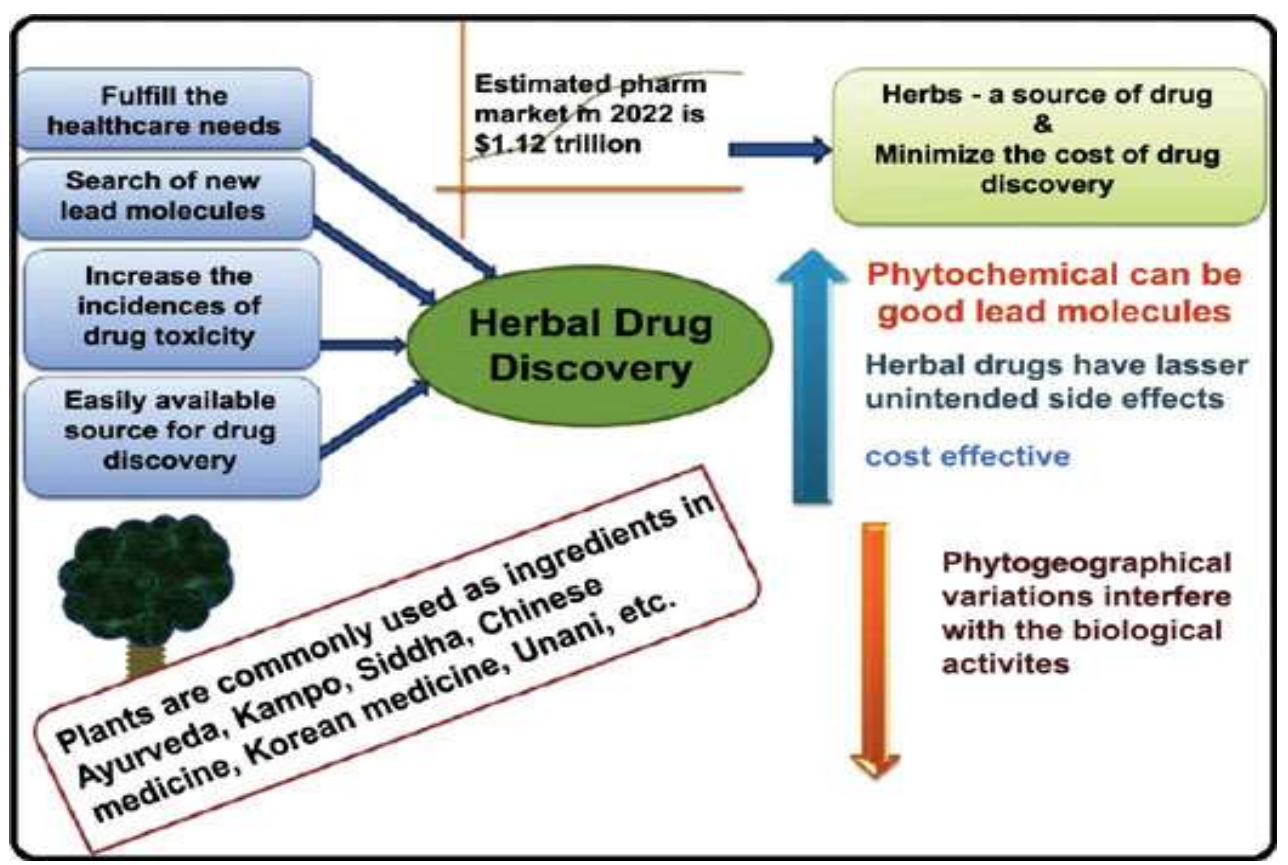

Figure:2, Source; https://www.eurekaselect.net/images/graphical-abstract/cppm/16/1/003.jpg

The objective of the research approach is the targeted isolation of new bioactive plant products, i.e., lead substances with novel structures and novel mechanisms of action. This approach has provided a few classical examples, but the problem most often encountered here is not enough availability. The problem of availability can be overcome by semi-synthesis/synthesis or using tissue-culture techniques (by genetically modifying the biosynthetic pathway of the compound of interest). ${ }^{[27]}$ As drug discovery from plants has traditionally been time-consuming, faster and better methodologies for plant collection, bioassay screening, compound isolation and its development must be employed (Koehn and Carter 2005). ${ }^{[28]}$ The design, determination and implementation of appropriate, clinically relevant, high throughput bioassays are difficult processes for all drug discovery programmers (Knowles and Gromo 2003; Kramer and Cohen 2004). Although the design of high-throughput screening assays can be challenging, once a screening assay is in place, compound and extract libraries can be tested for biological activity (Walters and Namchuk 2003).
WORLDWIDE TRADE OF HERBAL DRUGS

The global market for herbal medicines currently stands at over $\$ 60$ billion annually. The sale of herbal medicines is expected to get higher at $6.4 \%$ an average annual growth rate (Inamdar et al., 2008). Due to the contribution of numerous significant factors, the market of herbal medicines has grown at an expressive rate worldwide. ${ }^{[29]}$ Since millions of people all over the world have been using herbal medicines for thousands of years; great interest in alternative medicines; preference of populations for preventive medicine due to increasing population age; the belief that herbal medicines might be of effective benefit in the treatment of certain diseases where conventional therapies and medicines have proven to be inadequate; tendency towards self-medication; improvement in quality, proof of efficacy and safety of herbal medicines and high cost of synthetic medicines (Calixto 2000). ${ }^{[30]}$ According to World Health Organization, herbal medicines are lucrative globally and they represent a market value of about US \$43 billion a year (Christie, 2001). 


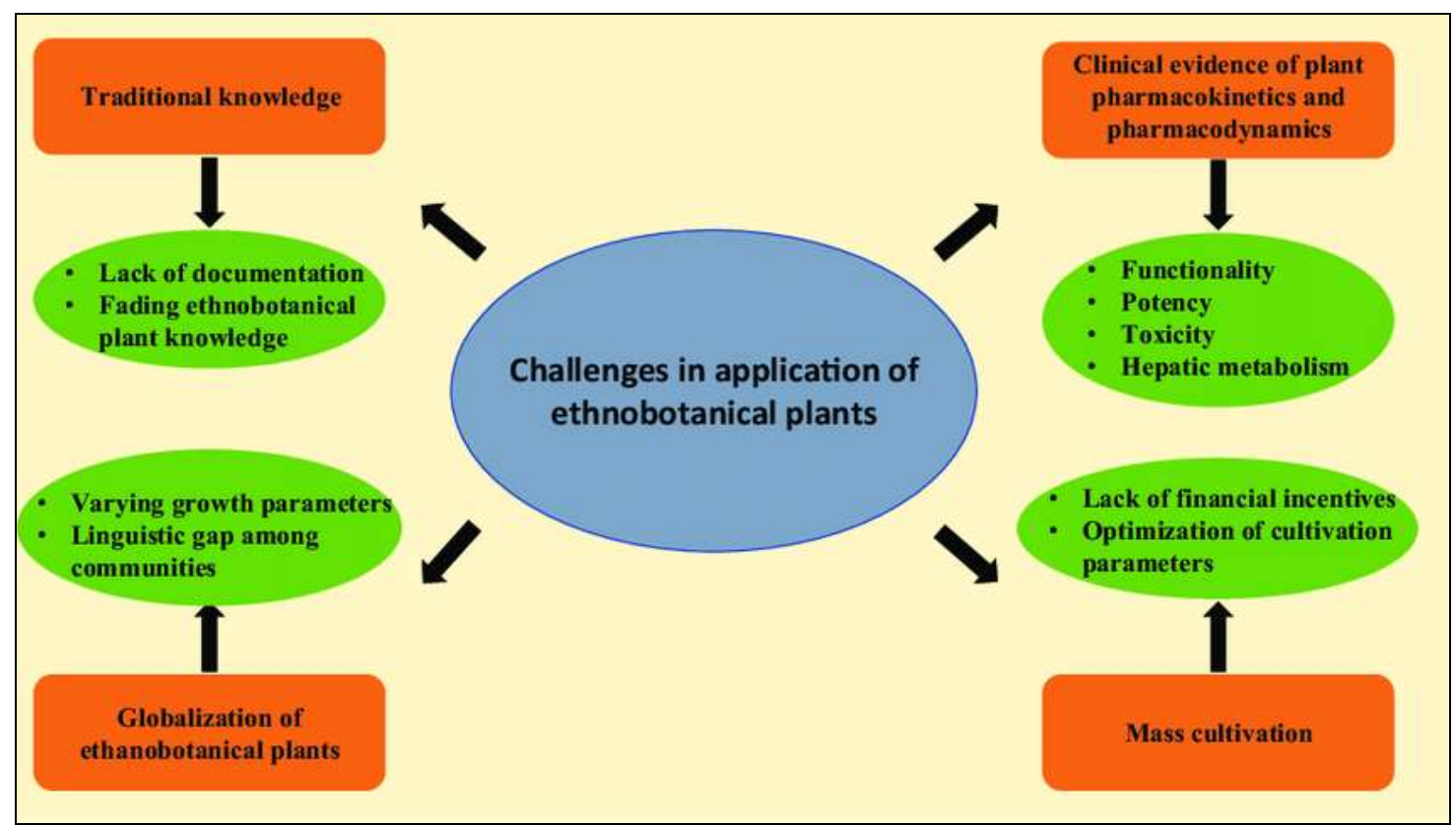

Figure:3, Source; https://www.researchgate.net/profile/Aseesh Pandey/publication/346563831/figure/fig1/AS:964237786624008@1606903611620/Gaps-andchallenges-for-drug-discovery-from-traditional-knowledge-on-medicinal-plants.png

\section{PAIN}

In medicine, pain is considered as highly subjective. A definition that is widely used in nursing was first given as early as 1968: "Pain is whatever the experiencing person says it is, existing whenever he says it does" (McCarffery, 1968). It is a major symptom in many medical conditions, significantly interfering with a person's quality of life and general functioning. Diagnosis is based on characterizing pain in various ways, according to duration, intensity, type (dull, burning, throbbing or stabbing), source, or location in body. ${ }^{[31]}$ Usually pain stops without treatment or responds to simple measures such as resting or taking an analgesic, and it is then called 'acute' pain. But it may also become intractable and develop into a condition called chronic pain, in which pain is no longer considered a symptom but an illness by itself. The study of pain has in recent years attracted many different fields such as pharmacology, neurobiology, nursing, dentistry, physiotherapy, and psychology. Pain medicine is a separate subspecialty figuring under some medical specialties like anesthesiology, physiatrist, neurology, and psychiatry. ${ }^{[32]}$

Pain typically consists of unpleasantness, motivation to withdraw or protect, and an awareness of the quality, location, intensity and duration of the pain, though it is possible to experience pain in the absence of one or more of these elements. Pain is often accompanied 13 deficits) (Merskey, 1994). For scientific and clinical purposes, pain is defined by the
International Association for the Study of Pain (IASP) as an unpleasant sensory and emotional experience associated with actual or potential tissue damage, or described in terms of such ${ }^{[33]}$ damage (Merskey, 1994). Pain is unquestionably a sensation in a part or parts of the body, and is also always unpleasant and therefore also an emotional experience.

Experiences which resemble pain but are not unpleasant, e.g., pricking, should not be called pain. Unpleasant abnormal experiences (dysesthesias) may also be pain but are not necessarily so because, subjectively, they may not have the usual sensory qualities of pain. Many people report pain in the absence of tissue damage or any likely pathophysiological cause; usually this happens for psychological reasons. There is usually no way to distinguish such experience from that due to tissue damage if it is taken as the subjective report. Inflammation and nociception both produce pain. ${ }^{[34]}$

\section{CLASSIFICATION OF PAIN}

Pain has constantly been described as a symptom. However, current advances in the understanding of neural mechanisms have confirmed that unrelieved pain may lead to changes in the nervous system and as such pain, particularly chronic pain, may be considered a disease in itself (Smith et al., 2000). Pain is categorized according to its duration, location and etiology. Pain classified by location is helpful in communicating and treating pain; chest pain will suggest angina or myocardial infarction which will need treatment according to cardiac care 
standards. Burns pain and post herpetic neuralgia are however examples of pain described by etiology. ${ }^{[35]}$ Pain can be divided into two broad categories generally: acute and chronic pain. Acute pain is also referred to as adaptive pain since it serves to protect the individual from further injury or promote healing. However, chronic pain has been called maladaptive, a pathologic function of the nervous system or pain as a disease (Calvino et al, 1968).

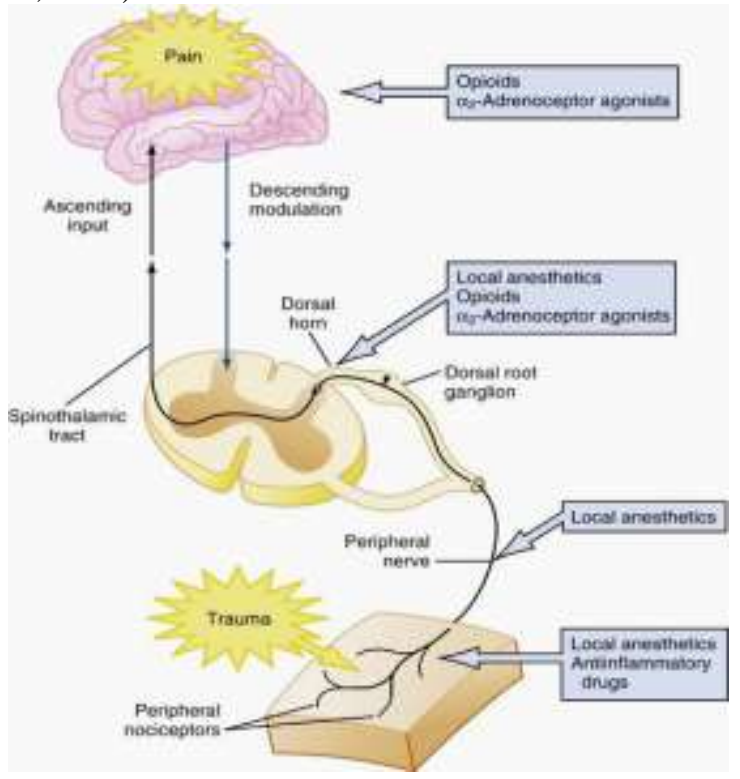

Figure:4, Source; https://clinicalgate.com/wpcontent/uploads/2015/02/B9781437727920000439 fo43-006-9781437727920.jpg

Acute pain: Acute pain is a warning that something is not right in the body. It is pain that occurs as a result of injury or surgery and is usually self-limiting, subsiding when the injury heals. It is of short duration and lasts less than 3 to 6 months. Acute pain is of recent onset and (probably) limited duration, usually having an identified temporal and causal relationship to injury or disease. Intensity of acute pain is from mild to severe and it is use to describe conditions, such as post-operative pain, pain following trauma or procedural pain. Somatic acute pain arises from injury to skin, bone, joint, muscle, and connective tissue, and it is generally localized to the site of injury (Abdel-Salem and ElBatran, 2005; Calvino et al., 1988; Schim and Stang, 2004). ${ }^{[36]}$

Chronic pain: Chronic pain is pain that persists beyond the point at which healing would be expected to be complete, or that occurring in disease processes in which healing does not take place, may be accompanied by severe psychological and social disturbance and usually lasts longer than six months and ranges in intensity from mild to severe (DeLeo, 2006). Chronic pain associated with malignancy includes the pain of cancer, acquired immunodeficiency syndrome
(AIDS), multiple sclerosis, sickle cell disease, and end-stage organ system failure. The exact cause of chronic pain of a non-malignant nature may or may not be known (DeLeo, 2006). This type of pain includes the pain associated with various neuropathic and musculoskeletal disorders such as headaches, fibromyalgia, rheumatoid arthritis, and osteoarthritis. $^{[37]}$ It is now known that in chronic pain, presynaptic receptors on sensory nerve terminals in the periphery contribute to increased excitability of sensory nerve endings (peripheral sensitization) (Agarwal et al., 2007). The hyper excitable sensory neuron bombards the spinal cord, leading to increased excitability and synaptic alterations in the dorsal horn. Such changes appear to be important in chronic inflammatory and neuropathic pain states (Agarwal et al., 2007; Trevisani et al., 2007).

\section{Types of pain}

Several distinct types of pain have been described based on their pathophysiology: nociceptive, inflammatory, neuropathic, and functional. The description of the pain may be indicative of the type of pain, for example the pain may be described as sharp, dull, pin and needle, burning, knawing, etc.

Nociceptive pain: Nociceptive pain is a transient pain in response to a noxious stimulus at nociceptors that are located in cutaneous tissue, bone, muscle, connective tissue, vessels, and viscera. Nociception may be thermal, chemical, or mechanical. The nociceptive system extends from the receptors in the periphery to the spinal cord, brain stem, ${ }^{[38]}$ and to the cerebral cortex where pain sensation is perceived. This system is a key physiological function that prevents further tissue damage due to the body's autonomic withdrawal reflex (Baron and Treede, 2007; Messeguer et al., 2006; Suardiaz et al., 2007).

When tissue damage occurs despite the nociceptive defense system, inflammatory pain ensues. The body now changes focus from protecting against painful stimuli to protecting the injured tissue. The inflammatory response contributes to pain hypersensitivity that serves to prevent contact or movement of the injured part until healing is complete, thus reducing further damage (Anseloni and Gold, 2008; Harvey and Dickenson, 2008). ${ }^{[39]}$

Neuropathic pain: Neuropathic pain is defined as spontaneous pain and hypersensitivity to pain associated with damage to or pathologic changes in the peripheral nervous system as in painful diabetic peripheral neuropathy (DPN), acquired immunodeficiency syndrome (AIDS), polyneuropathy, post-herpetic neuralgia (PHN); or pain originating in the central nervous system 
(CNS), that which occurs with spinal cord injury, multiple sclerosis, and stroke (Amado et al., 2007; Baron and Treede, 2007; Garcia-Larrea and Magnin, 2008). Functional pain, a relatively newer concept, is pain sensitivity due to an abnormal processing or function of the central nervous system in response to normal stimuli.

\section{Mechanism}

Stimulation of a nociceptor, due to a chemical, thermal, or mechanical event that has the potential to damage body tissue, may cause nociceptive pain. Damage to the nervous system itself, due to disease or trauma, may cause neuropathic (or neurogenic) pain. Neuropathic pain may refer to peripheral neuropathic pain, which is caused by damage to nerves, or to central neuropathic pain, which is caused by damage to the brain, brainstem, or spinal cord. ${ }^{[40]}$

\section{NOCICEPTIVE PAIN MAY BE CLASSIFIED FURTHER IN THREE TYPES THAT HAVE DISTINCT ORGANIC ORIGINS AND FELT QUALITIES.}

1. Superficial somatic pain (or cutaneous pain) is caused by injury to the skin or superficial tissues. Cutaneous nociceptors terminate just below the skin, and due to the high concentration of nerve endings, produce a sharp, well-defined, localized pain of short duration. Examples of injuries that produce cutaneous pain include minor wounds, and minor (first degree) burns.

2. Deep somatic pain originates from ligaments, tendons, bones, blood vessels, fasciae, and muscles. It is detected with somatic nociceptors. The scarcity of pain receptors in these areas produces a dull, aching, poorlylocalized pain of longer duration than cutaneous pain; examples include sprains, broken bones, and myofascial pain.

3. Visceral pain originates from body's viscera, or organs. Visceral nociceptors are located within body organs and internal cavities. The even greater scarcity of nociceptors in these areas produces pain that is usually more aching or cramping and of a longer duration than somatic pain. Visceral pain may be welllocalized, but often it is extremely difficult to localize, and several injuries to visceral tissue exhibit "referred" pain, where the sensation is localized to an area completely unrelated to the site of injury. ${ }^{[41]}$

4. Nociception is the unconscious afferent activity produced in the peripheral and central nervous system by stimuli that have the potential to damage tissue. It is initiated by nociceptors that can detect mechanical, thermal or chemical changes above a certain threshold. All nociceptors are free nerve endings of fast-conducting myelinated A delta fibers or slow-conducting unmyelinated $\mathrm{C}$ fibers, respectively responsible for fast, localized, sharp pain and slow, poorlylocalized, dull pain. Once stimulated, they transmit signals that travel along the spinal cord and within the brain. ${ }^{[42]}$ Nociception, even in the absence of pain, may trigger withdrawal reflexes and a variety of autonomic responses such as pallor, diaphoresis, bradycardia, hypotension, lightheadedness, nausea and fainting (Feinstein et al., 1954).

\section{THE DIMENSIONS OF PAIN}

Pain has been described in terms of its three "dimensions" (Melzack et al., 1968);

* Sensory-discriminative (location, intensity, quality, duration)

* Motivational-affective (unpleasantness and urge to escape the unpleasantness)

* Cognitive-evaluative

The effect of thinking on the intensity and unpleasantness of pain has been closely studied and an enormous effort has been put into devising cognitive and behavioral techniques for the amelioration of pain (Vlaeyen and Morley, 2005). Rainville et al (1997) tested Melzack and Casey's 1968 model using PET to monitor brain activity while their subjects' left hands were immersed in painfully hot water. Using hypnotic suggestion, these researchers were able to vary the unpleasantness experienced by their subjects, while keeping both the stimulus intensity and their subjects' perception of the pain intensity constant. ${ }^{[43]}$ It was found that this variation in perceived unpleasantness was mirrored by variation in activity in the anterior cingulate cortex (ACC) and concluded that, though many parts of the brain exhibit heightened activity during pain, and these regions are highly interactive, nevertheless "there appears to be at least a partial segregation of function between pain affect and sensation, with ACC activity possibly reflecting the emotional experience that provokes our reactions to pain" (Melzack et al., 1968; Rainville et al., 1997). ${ }^{[44]}$

Neuroimaging support for the involvement of the anterior cingulate cortex in pain's unpleasantness was not entirely unexpected. It had been known for decades that surgical removal of the anterior cingulate relieves the distress of pain without affecting its intensity, and this surgical intervention is used even today in cases of extreme and otherwise incurable chronic pain (Foltz and White, 1962).

Diagnosis and assessment: To establish an understanding of an individual's pain, health-care 
practitioners will typically try to establish certain characteristics of the pain: site (localization), onset and offset, character, radiation, associated symptoms, time pattern, exacerbating and ameliorating factors, and severity. According to its duration, pain may be categorized as acute (short term), sub- acute (medium term), or chronic (long term). By using the gestalt of these characteristics, the source or cause of the pain can often be established. A complete diagnosis of pain will require also looking at the patient's general condition, symptoms, and history of illness or surgery. The physician may order blood tests, Xrays, scans, EMG, etc. Pain clinics may investigate the person's psychosocial history and situation.

Verbal characterization: A key characteristic of pain is its quality. Typical descriptions of pain quality include sharp, stabbing, tearing, squeezing, cramping, burning, lancinating (electric-shock like), or heaviness. It may be experienced as throbbing, dull, nauseating and shooting or a combination of these. Indeed, individuals who are clearly in extreme distress such as from a myocardial infarction may not describe the sensation as pain, but instead as an extreme heaviness on the chest. Another individual with pain in the same region and with the same intensity may describe the pain as tearing which would lead the practitioner to consider aortic dissection. Inflammatory pain is commonly associated with some degree of itch sensation, leading to a chronic urge to rub or otherwise stimulate the affected area. The difference between these diagnoses and many others rests on the quality of the pain. The McGill Pain Questionnaire is an instrument often used for verbal assessment of pain.

Intensity: Pain may range in intensity from slight through severe to agonizing and can appear as constant or intermittent. The threshold of pain varies widely between individuals. Many attempts have been made to create a pain scale that can be used to quantify pain, for instance on a numeric scale that ranges from 0 to 10 points. In this scale, zero would be no pain at all and ten would be the worst pain imaginable. The purpose of these scales is to monitor an individual's pain over time, allowing care-givers to see how a patient responds to therapy for example. Accurate quantification can also allow researchers to compare results between groups of patients.

Localization: Pains are usually called according to their subjective localization in a specific area or region of the body: headache, toothache, shoulder pain, abdominal pain, back pain, joint pain, myalgia, etc. Localization is not always accurate in defining the problematic area, although it will often help narrow the diagnostic possibilities. Some pain sensations may be diffuse (radiating) or referred. Radiation of pain occurs in neuralgia when stimulus of a nerve at one site is perceived as pain in the sensory distribution of that nerve. Sciatica, for instance, involves pain running down the back of the buttock, leg and bottom of foot that results from compression of a nerve root in the lumbar spine. Referred pain usually happens when sensory fibers from the viscera enter the same segment of the spinal cord as somatic nerves, i.e., those from superficial tissues. The sensory nerve from the viscera stimulates the nearby somatic nerve so that the pain localization in the brain is confused. A well-known example is when the pain of a heart attack is felt in the left arm rather than in the chest. ${ }^{[45]}$

Management: In general, physicians are more comfortable treating acute pain, which usually is caused by soft tissue damage, infection and/or inflammation among other causes. It is usually treated simultaneously with pharmaceuticals, commonly analgesics, or appropriate techniques for removing the cause and for controlling the pain sensation. The failure to treat acute pain properly may lead to chronic pain in some cases (Dahl and Moiniche, 1998; Greco et al., 2000).

Anesthesia: Anesthesia is the condition of having the feeling of pain and other sensations blocked by drugs that induces a lack of awareness. It may be a total or a minimal lack of awareness throughout the body (i.e., general anesthesia), or a lack of awareness in a part of the body (regional or local anesthesia).

Analgesia: Analgesia is an alteration of the sense of pain without loss of consciousness. The body possesses an endogenous analgesia system, which can be supplemented with painkillers or analgesic drugs to regulate nociception and pain. Analgesia may occur in thecentral nervous system or in peripheral nerves and nociceptors. The perception of pain can also be modified by the body according to the gate control theory of pain. ${ }^{[46]}$

The endogenous central analgesia system is mediated by three major components: the periaqueductal grey matter, the nucleus raphe magnus, and the nociception-inhibitory neurons within the dorsal horns of the spinal cord, which act to inhibit nociception- transmitting neurons also located in the spinal dorsal horn. The peripheral regulation consists of several different types of opioid receptors that are activated in response to the binding of the body's endorphins. These receptors, which exist in a variety of areas in the body, inhibit firing of neurons that would otherwise be stimulated to do so by nociceptors (Straube et al, 2009). 


\section{Alternative and complementary medicine}

A survey of American adults found pain was the most common reason that people use complementary and alternative medicine. Traditional Chinese medicine views pain as a 'blocked' qi, akin to electrical resistance, with treatments such as acupuncture claimed as more effective for non-traumatic pain than traumatic pain. Although the mechanism is not fully understood, acupuncture may stimulate the release of large quantities of endogenous opioids (Sapolsky, 1968). Pain treatment may be sought through the use of nutritional supplements such as curcumin, glucosamine, chondroitin, bromelain and omega-3 fatty acids. Hypnosis as well as diverse perceptional techniques provoking altered states of consciousness has proven to be of important help in the management of all types of pain (Ornstein and Sobel, 1988). Some kinds of physical manipulation or exercise are showing interesting results as well (Degood et al., 1997).

\section{INFLAMMATION}

Inflammation is considered to be a morbid process affecting some part of the body, characterized by excessive heat, swelling, pain, and redness. It is a common factor in arthritic diseases or osteoarthritis (Andrejus, 1988) and a cardinal host defense response to injury, tissue ischaemia, autoimmune responses or infectious agents. ${ }^{[47]}$ Many diseases are now recognized to have an inflammatory component as part of the pathophysiology (e.g. rheumatoid arthritis). Inflammation often elicits a generalized sequence of events known as the acute phase response which is characterized by classical features of swelling, redness, heat and often pain. The essence of inflammation is to contain and eradicate local injury and then initiate repair of the damage. ${ }^{[48]}$ It is a major component of the damage caused by auto-immune diseases, and is also a fundamental contributor to diseases such as cancer, diabetes, and cardiovascular disease. In health, acute inflammation is often self-limiting, but when the acute inflammatory response is "deranged" aberrant and exacerbated neutrophil responses can lead to tissue damage and chronic inflammatory squeal. ${ }^{[49]}$ Thus, chronic inflammation occurs when acute inflammation remains unresolved. Chronic inflammation is a slow smoldering reaction that continues for months or even years and involves destruction of tissue as well as local proliferation of cells and connective tissue. In terms of what is happening locally within the tissues, the changes can be divided into vascular and cellular events. ${ }^{[50]}$

The vascular events: These result in fluid exudation from vessels to the site of injury. The fluid exudates contain a variety of mediators which influence the cells in the vicinity and the blood vessels themselves. These include the components of four proteolytic enzymes cascades: the complement system, the coagulation system, the fibrinolytic system, and the kinin system. These components are proteases that are inactive in their native form; they are activated by proteolytic cleavage, each activated component then activating the next. The activation of these components gives rise to more inflammatory mediators. ${ }^{[51]}$

The cellular events: The cells that are involved in the mediation of inflammation include neutrophils, mast cells, tissue macrophages, platelets and leucocytes. From the blood, platelets and leucocytes move into the inflammatory area but the neutrophils, mast cells and tissue macrophages are normally present in tissues (Rang et al., 2003). ${ }^{[52]}$

Neutrophils: These are characteristic of inflammation in the early stages - they are the first cells to appear in an infected area, and any section of recently inflamed (within a couple of days or so) tissue viewed under a microscope will appear packed with them. They perform many important functions, including phagocytosis and the release of extracellular chemical messengers. Neutrophils only live for a couple of days in these interstitial areas, so if the inflammation persists for a longer duration then they are gradually replaced by longer lived monocytes.

Macrophages: These are large phagocytic leucocytes, which are able to travel outside of the circulatory system by moving across the cell membrane of capillary vessels and entering the areas between cells in pursuit of invading pathogens. These usually, act after neutrophils and are the most efficient of the phagocytes. They can eat substantial numbers of bacteria or other cells. The binding of bacterial molecules to receptors on the surface of a macrophage triggers it to engulf and destroy the bacteria through the generation of a "respiratory burst". Pathogens also stimulate the macrophage to produce chemokines, which summon other cells to the site of infection. These release Tumor Necrosis Factor alpha (TNF- $\alpha)$, IL-1 in response to activation of toll-like receptors.

Mast cells: They are a type of innate immune cell that resides in the connective tissue and in the mucous membranes, and are intimately associated with pathogen defense and wound healing, and are often also associated with allergy and anaphylaxis. When activated by stretch receptors, mast cells rapidly release characteristic granules, rich in histamine and heparin, along with various hormonal mediators, and chemokines, or chemotactic cytokines into the environment. Histamine dilates blood vessels, causing the characteristic signs of inflammation, and also recruits neutrophils and macrophages. This is 
especially important in cases of trauma. Generally, mast cells make molecules that help repair traumatic injuries, including those involved with blood clotting (Stvrtinova et al, 1995; Johnson, 1994. ${ }^{[53]}$

Leucocytes: Various leucocytes are involved in the initiation and maintenance of inflammation. These cells can further be stimulated to maintain inflammation through the action of adaptive cascade through lymphocytes: T Cells, B Cells, and antibodies.

\section{Characteristics of inflammation}

The redness/heat associated with an inflamed tissue is caused by increased blood supply to the affected area. Blood vessels are vasodilated upstream of an infected area while capillary permeability to the affected tissue is increased, resulting in a loss of blood plasma. Vasoconstriction downstream of the infected area further increases oedema/swelling. The swelling distends the tissues, compresses nerve-endings and thus causes pain. The WBCs/leucocytes take on an important role in inflammation; they extravagate from the capillaries into tissues, and carry on as phagocytes picking up bacteria and cellular debris. They may also aid by walling off an infection and preventing its spread. If inflammation persists, released cytokines IL-1 and Tumor Necrosis Factor (TNF) will activate endothelial cells to upregulate receptors VCAM, ICAM-1, E-selection and L- selection for various immune cells. ${ }^{[54]}$

\section{Importance of inflammation}

It is one of the first responses of the immune system to infection or irritation. Inflammation serves to establish a physical barrier against the spread of infection and to promote healing of any damaged tissue following the clearance of pathogens. Mechanistically, inflammation results in the recruitment of cells, called neutrophils, to the site of injury. Neutrophils then trigger the immune system by releasing factors that summon other innate immune cells and lymphocytes. The inflammatory response is characterized by the following quintet: redness, heat, swelling, pain and possible dysfunction of the organs or tissues involved. Inflammation is stimulated by chemical factors released by injured cells. These factors (histamine, bradicine, serotonin, leukotrienes) sensitize pain receptors, cause vasodilation of the blood vessels at the scene, and attract phagocytes, especially neutrophils (Stvrtinova et al., 1995).

\section{Resolution of inflammation}

When inflammation subsides, the damaged tissue is repaired. Depending on the severity of the inflammation and the type of tissue involved repairs may or may not be complete; in minor inflammations of the skin, for example, the tissue is capable of complete regeneration whereas in nervous tissue regeneration may be limited and the damaged cells may be replaced with scar tissue. ${ }^{[55]}$

\section{Plant Description of Maytenus emarginata}

Maytenus emarginata (Willd.) Ding Hou belongs to family Celastraceae, is an evergreen tree that tolerates various types of stresses of the desert, locally known as "Kankero" in Hindi, "Thorny staff tree" in English (Kirtikar and Basu, 2000; Nair and Henry, 1983). It is found through in India (Madhya Pradesh, Uttar Pradesh, Punjab, Maharashtra, Gujarat, Delhi, Bihar, Tamilnadu, and Rajasthan) (Sagwan etal., 2011). Plants of this family generally grow as small trees, bushes or lianas and have resinous stems and leaves. They have been valued since antiquity because their extracts have useful medicinal properties (Crombie et al., 1990).

The crude plant extracts of the celastraceae in traditional medicine and agriculture is astonishing, and includes stimulant, restorative, male contraceptive, anti-tumor, anti- leukemic, antibacterial, insecticidal and insect repellent activities (Dubravkova et al., 1998). Various parts of this plant contain immense medicinal properties (Hussein et al, 1999). Traditionally species of Maytenus has been used for fever, asthma, rheumatism and gastrointestinal disorders worldwide. ${ }^{[56]}$ Recently some biomolecules from Maytenus species has been reported to be active against HIV-Protease (Hussein et al, 1999) Carcinoma and leukemia (Tin-wa et al., 1971), Ulcers (Vilegas et al., 1999) and MDR (Multi Drug Resistance). Various parts of this plant contain immense medicinal properties which are mentioned under:

- Root: Used in gastrointestinal troubles, especially dysentery (Spivey et al., 2002).

- Stem: Tender shoots of the plant help for mouth ulcer. The bark is ground to a paste and applied with mustard oil to kill lice in the hair.

- Leaf: Pulverized leaves of Maytenus emarginata are given in milk to children as a vermifuge (Kothari et al., 2000). A decoction of the leafy twigs is used as a mouthwash to relieve toothache. Ash of leaves used to heal up sores and wound gives cooling effect. The leaves are burnt and mixed with ghee to form an ointment used to heal sores (Pullaiah, 2006). The tender leaves are chewed raw in the treatment of jaundice.

- Fruit: The fruits are used in medicines to purify blood (Agarwal and Nag, 2009). ${ }^{[57]}$ 
Taxonomical classification

Kingdom: Plantae

Phylum: Magnoliophyta

Class: Magnoliopsida

Order: Celastrales

Family: Celastraceae

Genus: Maytenus

Synonyms:

* Celastrus emarginatus Willd;

* Gymnosporia emarginata (Willd.) Thw.;

* Gymnosporia Montana (Roth) Benth.

\section{Common Names:}

Hindi: Vinger, Kankero, Baikal, Malkangni

English: Thorny staff tree Sanskrit: Vikankata, Sudhavridsha Bengali: Bakundri, Vaichigacha Kannada: Tandrasi, Tandraja, Haalu manike Malayalam: Katou-patsjotti Marathi: Baefal, Baekar, Bhaaroolee Tamil: Kattangi, Nandunarani, Telugu: Chinni, Danthi, Sinni, Danti, Chinni Gujarati: Vickado.

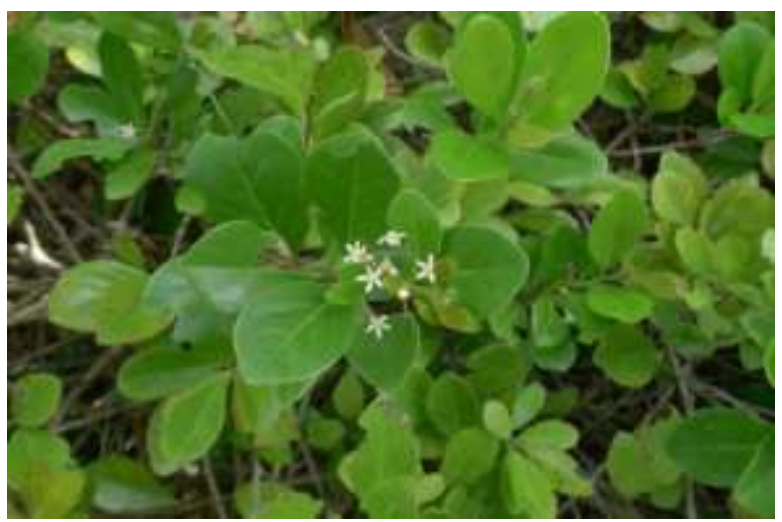

Figure:5, Leaves of Maytenus emarginata

\section{Botanical description}

The members of Celastraceae family generally are trees and shrubs comprising about 55 genera and 850 species that are sometimes climbing or vining (Bhandari, 1990).

Maytenus emarginata is a small, compact tree, 3-5meter-high; young branches purple, often spiny, with leaves and flowers on the spines.

Bark: Pale brown, smooth, cracked

Leaf: Thick, coriaceous and usually longer than $40 \mathrm{~mm}$, apex rounded, alternate on young branch lets, fasciculate on older ones.

Flower: Bisexual or sometimes functionally unisexual, actinomorphic, white or cream colored $5-7 \mathrm{~mm}$ in diameter.
Male flower: Stamens slightly shorter than petals, stigmas absent, disc green

Female flower: Staminodes shorter than stamens of male flower, ovary 3-locular, green, style as long as ovary.

Fruit: Capsule, berry, 6-12 mm long, green becoming red.

Root: Tap root, Cream yellow in color.

Distribution: The species is globally distributed in Pleotropic. Within India, it is common in dry scrub forests throughout, particularly on poor soils in Central and Western peninsular India. The genus Maytenus distributed in drier parts of Central, South-Western and North- Western India. It is found through in India (Madhya Pradesh, Uttar Pradesh, Punjab, Maharashtra, Gujarat, Delhi, Bihar, Tamilnadu, and Rajasthan). In Rajasthan it's found in Ajmer: Ajmer-Udaipur road, kota: Shahabad, Pali: Gurupratap singh village, Sirohi: Vadakhoda, Tonk: Rajmahal, Doogor Beed (Nagaur), Fahelpur Beed (Sikar), Siker Beed (Siker), Nokha (Bikaner), Karni Mata Oran, Deshnoke (Bikaner), Shri Balaji (Nagaur), Chohta (Barmer), Shri Mukam-Nokha (Bikaner), Khejarali (Jodhpur), Nursery of Rajasthan University, Jhalana Dungri (Jaipur).

\section{PHYTOCHEMICAL REVIEW}

Sesquiterpene pyridine alkaloids: Four new sesquiterpene alkaloids, Emarginatinine-C, Emarginatinine-D, Emarginatinine-E and emarginatinine, were isolated from Maytenus emarginata. Emarginatinine-E and emarginatinine showed cytotoxicity against human KB cells $\left(\mathrm{ED}_{50}\right.$ $=2.5$ and $2.1 \mu \mathrm{g} \mathrm{ml}^{-1}$, respectively). The structural determinations and activity relationships of these new compounds, and of emarginatine-A and emarginatine-B are discussed (HaurKuo, Y., 1994).

Macrolide sesquiterpene pyridine alkaloids: Two new macrolide sesquiterpene pyridine alkaloids, Emarginatinine F (1) and emarginatine G (2), were isolated from Maytenus emarginata. The structural determinations of 1 and 2 by $2 \mathrm{~d} n m r$ techniques and spectral comparison with a related compound, emarginatine a, are discussed. Biological evaluation showed that emarginatine $f$ demonstrated strong cytotoxicity against human epidermoid carcinoma of the nasopharynx $(\mathrm{kb})$, ileocecal adenocarcinoma (hct-8), melanoma (rpmi-7951) and medulloblastoma (te-671) tumor cells, and against murine leukemia (Kuo Y. H et al.,1994). 


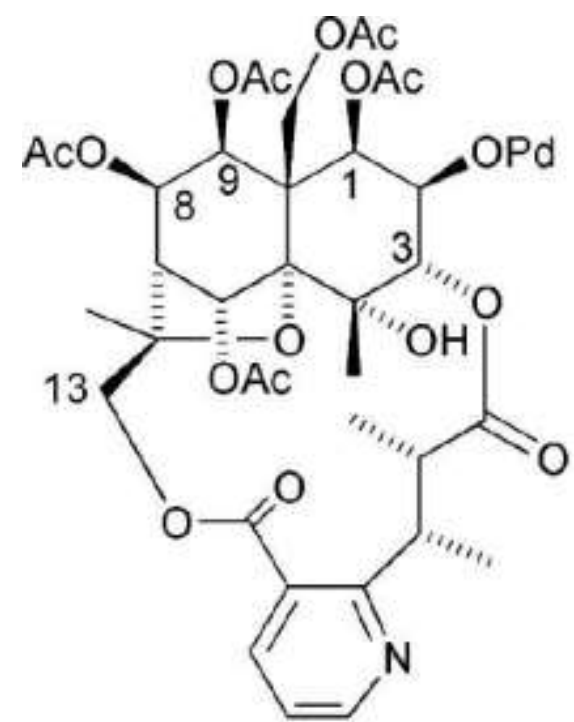

Emarginatine-A

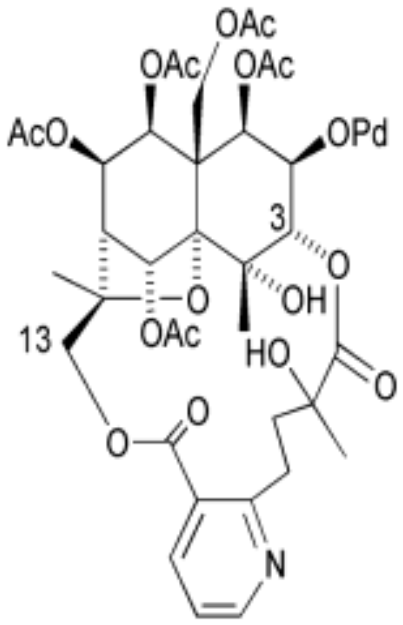

Emarginatinine

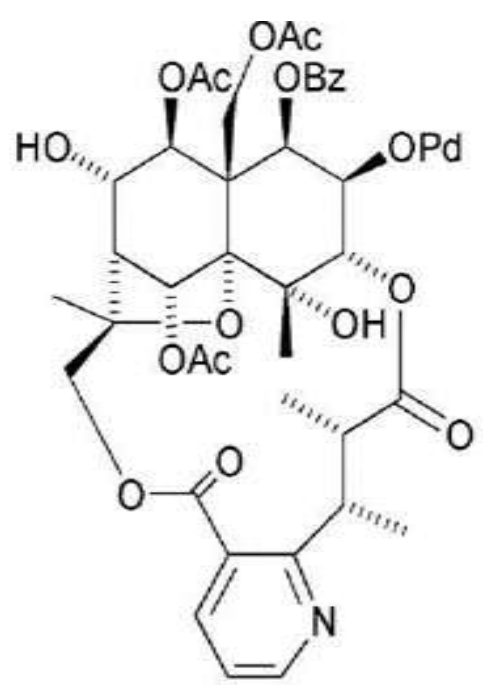

Cytotoxic emarginatine $\mathbf{F}$

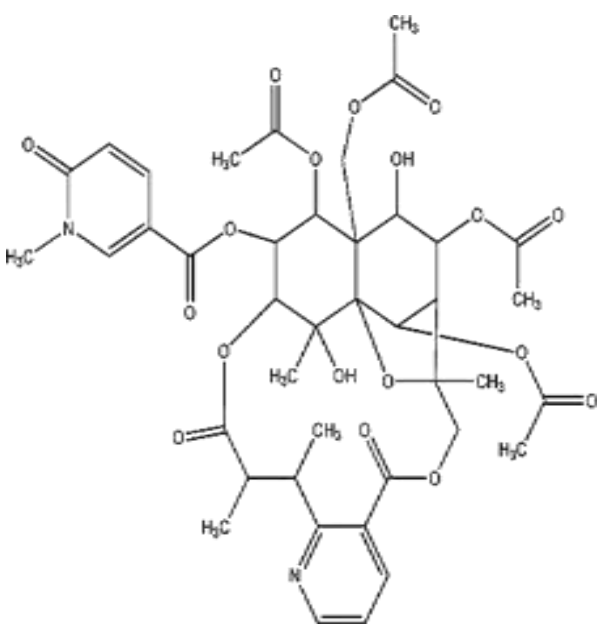

Emarginatine-C

Figure: 6 Chemical structures of some reported sesquiterpene pyridine alkaloids

\section{Flavonoids}

Plant parts in vivo and unorganized tissue in vitro of $M$. emarginata analyzed for qualitative and quantitative estimation of flavonoids, confirmed presence of kaempferol, luteolin and quercetin.<smiles></smiles>

Maximum amount was estimated of luteolin in all plant parts while minimum of quercetin. Amount of kaempferol was slightly lower than luteolin but higher than quercetin in all plant parts (Mathur and Goswami, 2014).<smiles>O=c1cc(-c2ccc(O)c(O)c2)oc2cc(O)cc(O)c12</smiles> 
<smiles>O=c1c(O)c(-c2ccc(O)c(O)c2)oc2cc(O)cc(O)c12</smiles>

\section{Quercetin \\ Figure:7 Chemical structures of some reported Flavonoid from M. emerginata}

\section{Pharmacological Studies}

Antibacterial activity: Leaf and stem of Maytenus emarginata was evaluated for its antibacterial potential and polyphenol content. The extraction was done by individual cold percolation method using six different solvents viz., hexane, toluene, ethyl acetate, acetone, methanol and water. Phenolic and flavonoid content of different extracts was determined using Folin- ciocalteu assays and aluminum chloride colorimetric method respectively. The solvent extracts of stem showed better antibacterial activity than a leaf. This may be because of the difference in the presence of phytoconsituents present in them (Moteriya, P., et al., 2014).

Cancer Therapy: Phytochemical investigation of Maytenus emarginata (Willd.) has been compiled for the study of clinical use of this plant. The active compounds include emarginatine $[\mathrm{A}],[\mathrm{B}],[\mathrm{E}],[\mathrm{F}]$, [G] and emarginatinine are discussed briefly with the recent advances and mechanism of their action. This article briefly reviews the botany, distribution, ecology, uses of the plant and as a drug for cancer therapy. This is an attempt to compile and document information on different aspect of Maytenus emarginata and its potential use as a drug source for different tumor cells (Sagwan, S., et al., 2011).

Hepatoprotective: Paracetamol (PCM) is widely used as analgesic and antipyretic drug, but at high dose it leads to undesirable side effects, such as hepatotoxicity. The present study demonstrates the comparative Hepatoprotective and antioxidative activity of Phyllanthus niruri, Maytenus emarginata, Eclipta Alba, Aloe Vera, Solanum indicum and Aegle marmelos against paracetamol induced toxicity (Parmar, S. R., 2010).

Histopathological examination and elevation of biochemical marker enzymes ALP, ALT and AST along with decreased levels of serum total protein and serum albumin confirmed the liver injury produced by Paracetamol. Treatment of rats with Maytenus emarginata extract showed significant reduction in levels of serum ALP, ALT and AST with elevation of serum protein and albumin near to normal in a dose dependent manner. Dose of 150 $\mathrm{mg} / \mathrm{kg}$ B.W. of Maytenus emarginata extract showed significant effects comparable to the effects showed by standard treatment drug Silymarin 100 $\mathrm{mg} / \mathrm{kg}$ B.W. orally. Maytenus emarginata ethanol extract possess potent hepatoprotective effect (Pathan. M. M. 2014).

Anticancer Activity: Leaves and stems of Maytenus emarginata were extracted with methanol to produce respective extracts. The extracts were screened for anti-cancer activity by using Antimitotic activity by Allium cepa method, Seed germination assay by green gram seeds and Brine shrimp lethality test using Artemia salina eggs. Methotrexate was used as standard anticancer drug. Current study demonstrates that the obtained results of leaves extracts were more potent than the stems extracts (Nagaveni, P., 2015).

Antimicrobial property: Stem (St), leaf (Lf), root (Rt), and fruit (Ft) of Maytenus emarginata (Willd.) Ding hou was evaluated for its phytochemicals and antibacterial potential. The Soxhlet extraction was done by using three different solvents viz., acetone, methanol and water. Qualitative phytochemical analysis of the crude powder extracts of $M$. emarginata stem, leaf, root and fruit was carried out for various phytoconstituents. The antimicrobial activity was evaluated by an agar disc diffusion method against four bacterial strain and two fungal strain (Dhawale, P.G and Ghyare, B.P., 2016).

Antioxidant Activities: Antioxidant activity of the methanol extract of Maytenus emarginata was determined by DPPH free radical nitric oxide scavenging assays, superoxide ion scavenging assays, ABTS, and iron chelating methods. Preliminary phytochemical screening revealed that the extract of Maytenus emarginata leaves 
possesses phenols, flavonoids, steroids, glycosides, saponins, tannins, and triterpenoids. The extract showed significant activities in all antioxidant assays compared to the standard antioxidant (ascorbic acid) in a dose-dependent manner, and remarkable activities to scavenge ROS may be attributed by the presence of the above active compounds in the leaves. The amount of total phenolics and flavonoid contents were also estimated. The DPPH, ABTS, Nitric oxide, superoxide, and iron chelating IC50 values of the methanolic extracts were 12.44, 24.27, 22.41, 5.85, and $2.74 \mu \mathrm{g} / \mathrm{mL}$, respectively. The total phenolic content of the methanolic extract was $10.69 \mathrm{mg}$ $\mathrm{CA} / \mathrm{g}$, whereas the total flavonoid was $1.56 \mathrm{mg}$ $\mathrm{CAE} / \mathrm{g}$. The antioxidant activities were correlated with the total phenolic content (Gupta, V.,).

Anti- Hyperglycemic Activity: Diabetes mellitus is a disease that is affecting major population of the world. This study aimed to evaluate the antiHyperglycemic activity of the hydro alcoholic extract of the leaves of Maytenus emarginatus plant which is widely found in dry and arid regions of India mainly in Rajasthan. The hydroalcholic extract of the leaves of $M$. emarginata (250 and $500 \mathrm{mg} / \mathrm{kg} /$ day) were administered orally to streptozotocin induced diabetic rats $(n=6 /$ group $)$ for 21 days. Changes in body weight, food and water intake, biochemical markers, fasting glucose levels and oral glucose tolerance test were evaluated. The results showed that the $M$. emarginatus dried extract (250 and $500 \mathrm{mg} / \mathrm{kg}$ ) reduced significantly the level of blood glucose comparable to glibenclamide $(10 \mathrm{mg} / \mathrm{kg})$ throughout the evaluation period and improved metabolic status of the animals and ameliorate the oral tolerance glucose test. Thus, we conclude that the extract of the leaves of $M$. emarginatus has antihyperglycemic activity (Bishnoi, N., et al 2016).

Antifertility Activity: Many plants have been explored for their fertility regulating properties around the world including India and China in search to discover a male contraceptive agent because humans depend on plant products as sources of herbal therapeutic agents without causing any side effects. The present study was planned to evaluate antifertility and reversible contraceptive activity, therefore, 50\% methanolic extracts of Maytenus emarginata leaves was prepared according WHO guidelines and administered orally at the dose of 50, 100, 200 $\mathrm{mg} / \mathrm{kg} /$ body $\mathrm{wt} /$ day for 60 days to develop an orally effective and reversible male contraceptive. Results of the present study reveal a significant decline in the sperms motility and density of extract treated rats as compared to control. The weight of seminal vesicles and testes was significant decreased in rats followed extract treatment suggests anti-androgenic effects in rats. Proteins, ascorbic acid, cholesterol and fructose contents in testis and sex accessory reproductive organs, as well as FSH, Testosterone hormones levels were decreased in rats treated with the extract (Mali, P.C., 2017).

Anti-ulcerogenic Activity: Anti-ulcer activity was evaluated with ethyl acetate and chloroform fractions of ethanolic extract of $M$. emarginata Willd. Using an aspirin induced pylorus ligation modelin rats as acute study for 4 days. Wistar albino rats either male or female were divided into six groups (Standard, control and 4 groups for two different doses 125 and $200 \mathrm{mg} / \mathrm{kg}$ body weight of ethyl acetate and chloroform fractions), each group consisting of six animals. The parameters taken to assess antiulcer activity were volume of gastric secretion, $\mathrm{pH}$, free acidity, total acidity and ulcer index. The results indicate that the ethyl acetate fraction of ethanolic extract significantly $(P<0.05)$ increases $\mathrm{pH}$ and decreases the volume of gastric acid secretion, free acidity, total acidity and ulcer index with respect to control at a dose of 200 $\mathrm{mg} / \mathrm{kg}$ body weight (Poonia L., 2014).

Antipyretic Activity: The pharmacological screening of the crude extract was carried out using standard protocols. The crude extract was suspended in $0.5 \%$ carboxy methyl cellulose (CMC) for administration to albino rats. $15 \%$ of yeast was suspended in this prepared $0.5 \% \mathrm{w} / \mathrm{v}$ carboxy methyl cellulose solution. It was revealed that the extract showed dose dependent antipyretic activity. The polyphyto leaf extract showed significant decrease in body temperature (Sandhya, S. M., 2012).

Nephrotoxicity: Histopathological examination and elevation of biochemical marker enzymes serum creatinine and BUN confirmed the kidney injury produced by Paracetamol. Treatment of rats with $M$. emarginata extract showed significant reduction in levels of serum creatinine near to normal in a dose dependent manner. Dose of 150 $\mathrm{mg} / \mathrm{kg}$ B.W. of Maytenus emarginata extract showed significant effects comparable to the healthy control group rats. $M$. emarginata extract possesses potent nephroprotective effects against the Paracetamol induced nephrotoxicity (Pathan, M.M et al., 2013).

\section{CONCLUSION}

Challenges in bioassay screening remain an important issue in the future of drug discovery from medicinal plants. Natural products, in general, are typically isolated in small quantities that are insufficient for lead optimization, lead development and clinical trials. Thus, there is a 
need to develop collaborations with synthetic and medicinal chemists to explore the possibilities of its semi-synthesis or total synthesis (Federsel, 2003; Ley and Baxendale 2002; Lombardino and Lowe, 2004). One can also improve the natural products compound development by creating natural products libraries that combine the features of natural products with combinatorial chemistry (Jachak and Saklani 2007).

Intensive phytochemical and pharmacological research efforts are underway worldwide to screen plants for active compounds and to develop new pharmaceutical products. These developments raised a number of important, controversial, ethical and legal issues related to intellectual property rights. Today, and in the decades to come, there is an urgent need to find out an equitable resolution, if future development of plant-based drugs, be they traditional, modern or more likely a hybrid of the two, is ever to serve the diverse health care needs of our global society (Grabley and Thiericke 1999; Clark., 1996).

\section{REFERENCES}

1. Sophomore A, Onayade Adedeji. The Role and Place of Medicinal Plants in the Strategies for Disease Prevention. 2013; 10(5): 210-229.

2. V. P. Kamboj. Herbal medicine, Current Science. 2000;78(1):35-39.

3. Pal S, Shukla Yogeshwer. Herbal medicine, Current status and the future November Asian Pacific journal of cancer prevention (APJCP).2002; 4(4):281-8.

4. Subhose $\mathrm{V}$ et al. Basic principles of pharmaceutical science in Ayurvěda, Bulletin of the Indian Institute of History of Medicine. 2005;35(2): 83-92.

5. Ballabh B, Chaurasia O P. Traditional medicinal plants of cold desert Ladakh-Used in treatment of cold, cough and fever, Journal of Ethnopharmacology. 2007;112(2):341-345.

6. Pandey M M et al. Indian herbal drug for general healthcare: an overview," The Internet Journal of Alternative Medicine. 2008;6(1):8-12.

7. Samy R P et al. Screening of 34 Indian medicinal plants for antibacterial properties," Journal of Ethnopharmacology. 1998; 62(2):173-181.

8. Samy R P, Ignacimuthu S. Antibacterial activity of some folklore medicinal plants used by tribals in Western Ghats of India," Journal of Ethnopharmacology. 2000;69(1):63-71.

9. Veale D J H et al. South African traditional herbal medicines used during pregnancy and childbirth," Journal of Ethnopharmacology. 1992;36(3):85-191.

10. Abegaz BM, Ngadjui BT. Chemistry of Marketed Plants of Eastern and Southern Africa Nigeria. 1999;3(19):14-25

11. Agyare $\mathrm{C}$ et al. An ethno-pharmacological survey and in vitro confirmation of ethnopharmacological use of medicinal plants use for wounds healing in Bosomtwi-Atwima-Kwanwoma area, Ghana. $J$ Ethnopharmacol. 2009;25(3):393-403.

12. Fokunang $\mathrm{C} \mathrm{N}$ et al. Traditional Medicine: Past, Present and Future Research and Development Prospects and Integration in the National Health System of Cameroon. 2011; 8(3): 284-295.

13. Atanasov A G et al. Discovery and resupply of pharmacologically active plant-derived natural products: a review. Biotechnol. 2015;33(2):1582-1614.

14. Harvey et al. The re-emergence of natural products for drug discovery in the genomics. 2015;14(1):111129.

15. Newman, D J, Cragg G M. Natural products as sources of new drugs from 1981 to 2014. 2016;79:629-661.

16. Waltenberger B et al. Natural products to counteract the epidemic of cardiovascular and metabolic disorders. 2016;21:799-807.

17. Zongru G. The modification of natural products for medical use. 2017;7(2):119-136.

18. Balekundri A, Mannur V K. Quality control of the traditional herbs and herbal products. 2020;6:67-72.

19. Altemimi A, Lakhssassi Naoufal. Phytochemicals: Extraction, Isolation, and Identification of Bioactive Compounds from Plant Extracts. 2017;6: 42-48.

20. J Bouckaert, $\mathrm{R}$ Loris. Novel structures of plant lectins and their complexes with carbohydrates. 1999;9(5):572-7.

21. Kunle O F, Egharevba H O. Standardization of herbal medicines. 2012; 4(3):101-112.

22. Ingle KP et al. Phytochemicals: Extraction methods, identification, and detection of bioactive compounds from plant extracts. J Pharmacogn Phytochem. 2017;6:32-6.

23. Azwanida NN. A review on the extraction methods use in medicinal plants, principle, strength, and limitation. Med Aromat Plant. 2015;4:196.

24. Pandey A, Tripathi S. Concept of standardization, extraction, and pre-phytochemical screening strategies for herbal drug. J Pharmacogn Phytoche. 2014;2:115-9.

25. Rout Soumya, Das Lopamudra. Plants in traditional medicinal system-Future source on new drugs. 2009;5:8-43. 
26. Marcy J B et al. Drug discovery from medicinal plants, Life Sciences. 2005;78:431-441.

27. Ahmad Javed. Drug Discovery from Plant Sources: Scope, Approach and Challenges. 2020;10:1-13.

28. Philip Gribbon et al. High-throughput drug discovery: what can we expect from HTS? Drug Discovery. 2005;10(1):17-22

29. Nirmal S A, Pal S C. Contribution of Herbal Products In Global Market. 2013;2:17-22.

30. Ekor Martins. The growing use of herbal medicines: issues relating to adverse reactions and challenges in monitoring safety. 2013;4:177-88.

31. Ragda A A, Rafael Benoliel. Characterization of pain originating from oral mucosallesions. 2016;121(3):31-44.

32. Sharav Y, Benoliel R. The diagnostic process. Orofacial Pain and Headache. 2015;2:1-29.

33. Aydede M. Is feeling pain the perception of something? The Journal of Philosophy. 2009;106(10): 531567.

34. Backryd Emmanuel. Pain as the Perception of Someone: An Analysis of the Interface between Pain Medicine and Philosophy. 2019; 27:13-25.

35. Aydede M. Pain Perception or introspection? http://faculty.arts.ubc.ca/maydede/Ayded e_PainIntrospection. 2016;14:12-17.

36. Woolf C J et al. Towards a mechanism-based classification of pain. 1998;77: 227-229.

37. Brodal P. The central nervous system: Structure and function. 2016;1:204-214. Oxford University Press.

38. International association for the study of pain taxonomy-pain. http://www.iasp-pain.org/Taxonomy. Accessed November 5, 2015.

39. Kleggetveit, I P et al. High spontaneous activity of C-nociceptors in painful polyneuropathy. Pain. 2012;153(10): 2040-2047.

40. Yam M F, Loh Y C. General Pathways of Pain Sensation and the Major Neurotransmitters Involved in Pain Regulation. 2018;19:21-64.

41. Bishop G H, Landau W M. Evidence for a Double Peripheral Pathway for Pain. 1958;2(6):712-713.

42. Garland Eric L. Pain Processing in the Human Nervous System: A Selective Review of Nociceptive and Biobehavioral Pathways. 2012;39(3): 561-571.

43. Loeser JD, Melzack R. Pain: an overview. The Lancet. 1999;3(1):1607-1609.

44. Dubin A E, Patapoutian A. Nociceptors: The sensors of the pain pathway. 2010;1:60-72. [CrossRef] [PubMed]

45. Rebecca M, Fitzgerald M C. Nerve injury and neuropathic pain-A question of age. 2016;5(2):296-302.

46. Leonard M. Monheim. Analgesia in Dentistry Now and in the Futurem. 2019;66(4): 227-231.

47. Medzhitov R. Inflammation, new adventures of an old flame Cell. 2010;1:771-776.

48. Ferrero M L et al. Chronic inflammation: importance of NOD2 and NALP3 in interleukin-1 $\beta$ generation. 2007;147:227-235.

49. Nathan C, Ding A. Nonresolving inflammation. 2010;1:871-882.

50. Zhou Y et al. Triptolide Attenuates Inflammatory Response in Membranous Glomerulo-Nephritis Rat via Downregulation of NF-kB Signaling Pathway. 2016;41:901-910.

51. Takeuchi O, Akira S. Pattern Recognition Receptors and Inflammation. Cell. 2010;140:805-820.

52. Chertov $\mathrm{O}$ et al. Leukocyte granule proteins mobilize innate host defenses and adaptive immune responses. 2000;177:68-78.

53. Lawrence T. The Nuclear Factor NF-kB Pathway in Inflammation. CSH Perspect Biol. 2009;3(1):13-22.

54. Lawrence T. The Nuclear Factor NF-kB Pathway in Inflammation. CSH Perspect Biol. 2009;3(1):13-22.

55. Headland S E, Norling L V. The resolution of inflammation: Principles and challenges. Semin Immunol. 2015;27:149-160.

56. Khichar M K, Sharma M. Maytenus emarginata: A Folklore Ethnomedicinal Plant of Rajasthan. 2019;9(4):20-39.

57. Moteriya Pooja, Padalia Hemali. Phytochemical analysis and antibacterial activity of Maytenus emarginata leaf and stem. 2014;3(4):202-208. 